Article

\title{
Effect of SIFRCCs with Varying Steel Fiber Volume Fractions on Flexural Behavior
}

\author{
Seungwon Kim ${ }^{1,2} \mathbb{D}$, Cheolwoo Park ${ }^{1,2, * \mathbb{D}}$ and Yongjae Kim ${ }^{2, * \mathbb{D}}$ \\ 1 KIIT (Kangwon Institute of Inclusive Technology), Kangwon National University, 1 Gangwondaegil, \\ Chuncheon 24341, Korea; inncoms@kangwon.ac.kr \\ 2 Department of Civil Engineering, Kangwon National University, 346 Jungnag-ro, Samcheok 25913, Korea \\ * Correspondence: tigerpark@kangwon.ac.kr (C.P.); yzkim@kangwon.ac.kr (Y.K.); \\ Tel.: +82-33-570-6515 (C.P.); +82-33-570-6507 (Y.K.)
}

Received: 17 February 2020; Accepted: 16 March 2020; Published: 19 March 2020

check for updates

\begin{abstract}
Conventional concrete is a brittle material with a very low tensile strength as a result of compressive strength and tensile strain. In this study, the flexural behavior characteristics of slurry-infiltrated fiber-reinforced cementitious composites (SIFRCCs) based on slurry-infiltrated fiber concrete (SIFCON), such as high-performance fiber-reinforced cementitious composites (HPFRCCs), were analyzed to maximize the fiber volume fraction and increase resistance to loads with very short working times (such as explosions or impacts). For extensive experimental variables, one fiber aspect ratio and three fiber volume fractions $(6 \%, 5 \%$, and $4 \%$ ) were designed, and the flexural toughness and strength were figured out with respect to variables. A maximum flexural strength of $45 \mathrm{MPa}$ was presented for a fiber volume fraction of $6 \%$, and it was found that by increasing the fiber volume fraction the flexural strength and toughness increased. The test results with respect to fiber volume fraction revealed that after the initial crack, the load of SIFRCCs frequently increased because of the high fiber volume fraction. In addition to maximum strength, acceptable strength was found, which could have a positive effect on brittle fractures in structures where an accidental load is applied (such as an impact or explosion).
\end{abstract}

Keywords: slurry-infiltrated fiber-reinforced cementitious composites (SIFRCCs); flexural behavior; flexural strength; toughness; fiber volume fraction; unexpected load

\section{Introduction}

Conventional concrete is a brittle material with a low tensile strength as a result of compressive strength and tensile strain. To prevent the brittle fracturing of concrete materials while improving tensile behavior and energy dissipation capacity, high-performance fiber-reinforced cementitious composites (HPFRCCs) has been actively researched [1-6]. In general, adding steel fibers to concrete can delay the generation of initial cracks and restrain the progress of cracks. Moreover, a large increase in strength and toughness can be expected $[1-3,7,8]$.

Furthermore, owing to the recent rapid development of construction technology, structures are becoming larger, higher, and longer, and the functions of structures are becoming more diversified and complicated, resulting in an increasing trend of unexpected loads such as explosions and fires [1-3,9,10]. These structures are usually located in high-traffic and densely populated areas, which can cause difficulties in recovering the structure if the structure is damaged due to an explosion or an extreme load such as a shock or impact, and there is a risk of chain damage [1,11,12]. Ultra-high-performance concrete (UHPC) is a high-tech material that follows new technological rules regarding composition, production, and mechanical behavior, as well as design and the construction of structures [13]. The high packing density, especially of fine aggregates in the binder matrix, reduces the water demand of fresh mixes and 
increases compressive strength. Further, the brittleness of UHPC concrete permits a high compressive strength and improved durability [13]. Conventional concrete specimens fail catastrophically as a result of a single crack, and separated into two pieces. On the contrary, fiber-reinforced concrete specimens, even with low fiber volume fractions retain their post-cracking ability to carry out loads [14]. In recent years, different HPFRCCs have been developed to improve the mechanical performance, resilience and durability of concrete structures $[15,16]$. HPFRCCs have been expected to improve on the drawbacks of concrete and improve on impact resistance [17]. Most recently, river sand and high-volume supplementary cementitious materials such as fly ash and/or ground-granulated blast slag have been used to reduce material costs and carbon footprints $[15,16]$.

The typical defensive design used to respond to unexpected loads in existing structures has been to increase the thickness of concrete walls [11,12], but high-performance materials such as HPFRCCs provide other advantages that include improving the utilization of structures and the efficient reinforcement of work. However, while HPFRCCs have a high compressive strength, their tensile strength and strain capacity are slightly lower than their compressive strength performance. This may be the biggest issue for the limited fiber volume fraction of HPFCCs $[1,11,12]$. The increasing threat of global terrorism as well as general safety concerns has given rise to a need for reinforced concrete structures that can withstand sudden dynamic loads like impacts and blasts. The energy-absorbing capacity of a material plays an important role in developing protective structures, and fiber-reinforced concrete is becoming popular due to its greater impact-resistance properties [18].

This study develops a slurry-infiltrated fiber-reinforced cementitious composite (SIFRCCs) that can maximize flexural tensile strength and energy absorption by maximizing the amount of steel fibers needed to increase resistance to very short working loads such as explosions or shocks. SIFRCCs utilize a high-performance slurry to make high fiber-volume fractions possible. Unlike conventional HPFRCCs or fiber-reinforced concrete, SIFRCCs place the fibers first, then fill the high-performance slurry between the steel fibers. This study also analyzes flexural behavior characteristics in respect to steel fiber volume fractions, considering fiber volume fraction of $4 \%, 5 \%$ and $6 \%$.

\section{Experimental Details}

\subsection{Used Materials}

\subsubsection{Cement}

In this study, Type 1 ordinary Portland cement was used, the physical and chemical characteristics of which are listed in Table 1.

Table 1. Material properties of ordinary Portland cement [19-21].

\begin{tabular}{|c|c|c|c|c|c|}
\hline \multicolumn{6}{|c|}{ Physical Properties } \\
\hline \multirow{2}{*}{ Specific gravity } & \multirow{2}{*}{ Fineness $\left(\mathrm{cm}^{2} / \mathrm{g}\right)$} & \multirow{2}{*}{ Stability (\%) } & \multicolumn{2}{|c|}{ Setting time (min.) } & \multirow{2}{*}{ Loss on Ignition (\%) } \\
\hline & & & Initial & Final & \\
\hline 3.15 & 3400 & 0.10 & 230 & 410 & 2.58 \\
\hline \multicolumn{6}{|c|}{ Chemical Compositions (\%, Mass) } \\
\hline $\mathrm{SiO}_{2}$ & $\mathrm{CaO}$ & $\mathrm{MgO}$ & & & $\mathrm{Al}_{2} \mathrm{O}_{3}$ \\
\hline 21.95 & 60.12 & 3.32 & & & 6.59 \\
\hline
\end{tabular}

\subsubsection{Silica Fume}

Silica fume was used as an admixture to manifest the high strength of the high-performance slurry; its physical and chemical characteristics are shown in Table 2. 
Table 2. Material properties of silica fume [12,20].

\begin{tabular}{|c|c|c|c|c|}
\hline \multicolumn{5}{|c|}{ Physical Properties } \\
\hline \multicolumn{3}{|c|}{ Specific gravity } & \multicolumn{2}{|c|}{ Fineness $\left(\mathrm{cm}^{2} / \mathrm{g}\right)$} \\
\hline \multicolumn{3}{|c|}{2.10} & \multicolumn{2}{|c|}{200,000} \\
\hline \multicolumn{5}{|c|}{ Chemical Compositions (\%, Mass) } \\
\hline $\mathrm{SiO}_{2}$ & $\mathrm{CaO}$ & $\mathrm{MgO}$ & $\mathrm{SO}_{3}$ & $\mathrm{Al}_{2} \mathrm{O}_{3}$ \\
\hline 96.00 & 0.38 & 0.10 & - & 0.25 \\
\hline
\end{tabular}

\subsubsection{Aggregate}

Fine aggregate with a diameter of $0.5 \mathrm{~mm}$ or less was used to improve the filling performance of the slurry and reduce material separation. Furthermore, the ratio of the amount of binder to the fine aggregates was set at 1:0.5, with no coarse aggregate used for filling between steel fibers.

\subsubsection{High Range Water Reducer (HRWR)}

A polycarbonate-based high-range water reducer (HRWR), the properties of which are listed in Table 3, was used to improve the flow-ability and filling performance of the slurry.

Table 3. Properties of polycarboxylate high-range water reducer (HRWR) [12,20].

\begin{tabular}{ccccc}
\hline Principal Component & Specific Gravity & pH & Alkali Content (\%) & Chloride Content (\%) \\
\hline Polycarboxylate & $1.05 \pm 0.05$ & $5.0 \pm 1.5$ & less than 0.01 & less than 0.01 \\
\hline
\end{tabular}

\subsubsection{Steel Fiber}

In this study, steel fibers were used for conventional concrete with an aspect ratio of 80 (diameter $0.75 \mathrm{~mm}$, length $60 \mathrm{~mm}$ ). The tensile strength of the steel fibers was $1200 \mathrm{MPa}$.

\subsection{SIFRCCS}

For the high-performance slurry to fill the inside space of the steel fibers laid in advance, the water-binder ratio was fixed at 0.35 to provide the optimum filling performance through premixing, and the amount of HRWR was set at $2.5 \%$ of the binder weight. First, the prismatic mold of $100 \times 100 \times 350 \mathrm{~mm}$ was filled with steel fibers with respect to volume fraction. Steel fibers were randomly sprinkled in the mold so as not to overfill its depth, then leveled up as much as possible. Slurry was prepared after mixing the contents and poured until no more bubbles were seen, to ensure the infiltration of slurry into the fibers (as the void has negative effects on the strength of the concrete). In addition, to reduce material separation and achieve the required strength, amounts of fine aggregate and silica fume corresponding to $50 \%$ and $15 \%$ of the binder cement weights, respectively, were replaced before mixing $[1,10,11]$. Table 4 shows the mixing characteristics of the high-performance slurry used. In addition, flexure specimens of the three values of fiber volume fraction (i.e., $6 \%, 5 \%$, and $4 \%$ ) were fabricated using steel fibers with an aspect ratio of 80 [1]. The compressive and tensile strengths of the SIFRCCs are shown in Table 5.

Table 4. Mix proportions of slurry-infiltrated fiber-reinforced cementitious composites (SIFRCCs) [2,3,12,20].

\begin{tabular}{|c|c|c|c|c|c|c|c|}
\hline \multirow{2}{*}{$\begin{array}{c}\text { Fiber } \\
\text { (\% vol.) }\end{array}$} & \multirow{2}{*}{$\begin{array}{c}\text { W/B } \\
\text { (Water-Binder Ratio) }\end{array}$} & \multicolumn{6}{|c|}{ Unit Material Quantity $\left(\mathrm{kg} / \mathrm{m}^{3}\right)$} \\
\hline & & Water & Cement & Fine Aggregate & Silica Fume & Superplasticizer & Steel Fiber \\
\hline 4 & & & & & & & 312 \\
\hline 5 & 0.35 & 407.4 & 962.8 & 566.4 & 169.9 & 28.3 & 390 \\
\hline 6 & & & & & & & 468 \\
\hline
\end{tabular}


Table 5. Compressive and tensile strength of SIFRCCs [2,3].

\begin{tabular}{cccc}
\hline \multirow{2}{*}{ Mechanical Properties } & \multicolumn{3}{c}{ Fiber Volume Fraction } \\
\cline { 2 - 4 } & $\mathbf{4 \%}$ & $\mathbf{5 \%}$ & $\mathbf{6 \%}$ \\
\hline Compressive strength $(\mathrm{MPa})[3]$ & 65.5 & 74.5 & 82.9 \\
\hline Tensile strength $(\mathrm{MPa})[2]$ & 10.9 & 14.1 & 15.0 \\
\hline
\end{tabular}

\subsection{Experimental Method}

To evaluate the flexural performance of SIFRCCs with respect to the steel fiber volume fraction, prismatic specimens of $100 \times 100 \times 350 \mathrm{~mm}$ were fabricated in this study based on ASTM C 1609 [21], and bending tests were conducted. As shown in Figure 1, third-point loading was applied using a 200-ton universal testing machine. In addition, the deflection displacement at the center was taken using a Japanese yoke $[1,9,11,12]$, to which two linear variable differential transducers (LVDTs) were attached to the center of the specimen. The load was applied at the rate of $1 \mathrm{~mm} / \mathrm{min}$ in the displacement control method. To evaluate the flexural performance, the flexural strength was calculated using Equation (1) in ASTM C 1609 [21]. Figure 2 shows a drawing of the specimen and the Japanese yoke for LVDTs.

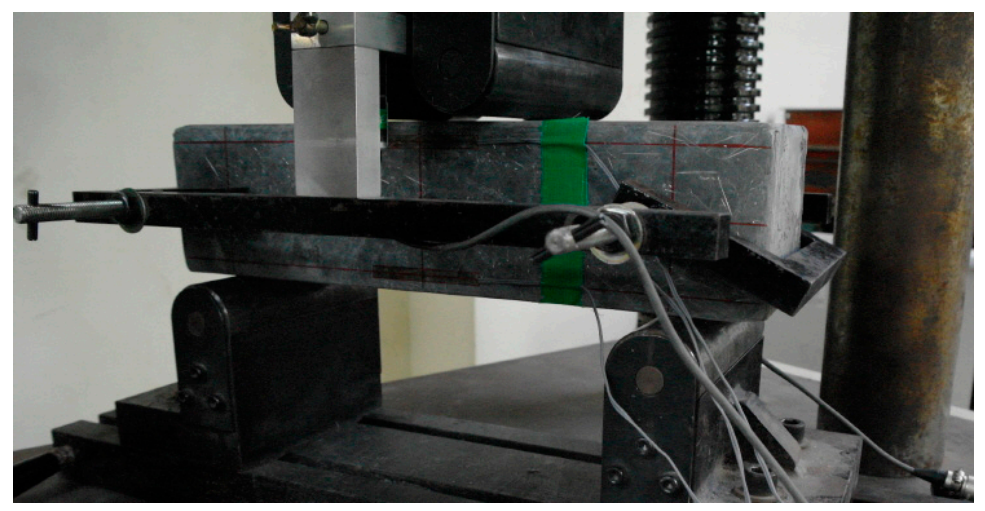

Figure 1. Bending test with third-point loading.
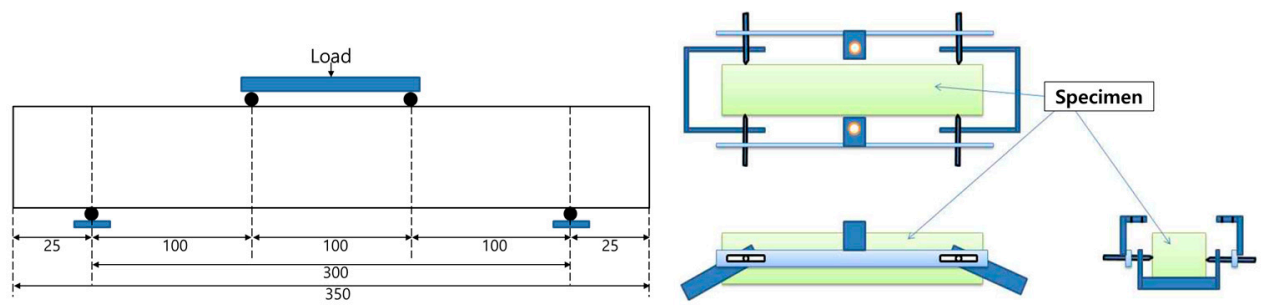

Figure 2. Drawing of the specimen and Japanese yoke for linear variable differential transducers (LVDTs).

$$
f=\frac{P L}{b d^{2}}
$$

where,

$\mathrm{P}=$ the maximum load;

$\mathrm{L}=$ the span distance $(300 \mathrm{~mm})$;

$\mathrm{b}=$ the specimen width $(100 \mathrm{~mm})$;

$\mathrm{d}=$ the specimen height $(100 \mathrm{~mm})$

To evaluate the energy absorption capacity with respect to the fiber volume fraction, the flexural toughness was calculated based on ASTM C 1609. However, it is inappropriate to define this as the area to $1 / 150$ of the span distance $L$ in the load-deflection curve, as suggested in ASTM 
C 1609 [21], because of the flexural behavior characteristics of SIFRCCs considered in this study. Therefore, to compare the energy absorption capacity with respect to the fiber volume fraction, the flexural toughness characteristics were instead analyzed using an area to $20 \mathrm{~mm}$ of deflection in the load-deflection curve $[1,9,11,12]$.

In addition, if the load at the first peak is assumed to have linear elastic behavior, then deflection at the first load peak point could be obtained through Equation (2), and this could be considered an initial crack [22]. At ASTM C 1609 [21], the deflection at the first peak point of loading for a test specimen measuring $100 \times 100 \times 350 \mathrm{~mm}$ is approximately $0.04 \mathrm{~mm}$ [12].

$$
\delta_{1}=\frac{23 P_{1} L^{3}}{1296 \mathrm{EI}}\left[1+\frac{216 d^{2}(1+\mu)}{115 L^{2}}\right]
$$

where,

$$
\begin{aligned}
& \delta_{1}=\text { the first-peak deflection }(\mathrm{mm}) \\
& P_{1}=\text { the first-peak load }(\mathrm{N}) \\
& L=\text { the span length }(\mathrm{mm}) \\
& E=\text { the estimated modulus of elasticity of the specimen }(\mathrm{MPa}) ; \\
& I=\text { the cross-sectional moment of inertia }\left(\mathrm{mm}^{4}\right) ; \\
& d=\text { the average depth of specimen at the fracture, as oriented for testing }(\mathrm{mm}) ; \\
& \mu=\text { the Poisson's ratio }
\end{aligned}
$$

\section{Experimental Results and Analysis}

\subsection{Flexural Behavior Characteristics}

Figures 3-5 show the load deflection curve with respect to the fiber volume fraction. The experimental results with a fiber volume fraction of $6 \%$ revealed a desirable flexural resistance performance at the maximum load of $149 \mathrm{kN}$. In addition, the residual strength continued increasing after the maximum strength was reached. This suggests that when extreme loads such as unexpected explosions and impacts are applied, the collapse of structures due to brittle fracturing can be prevented by obtaining additional residual strength.

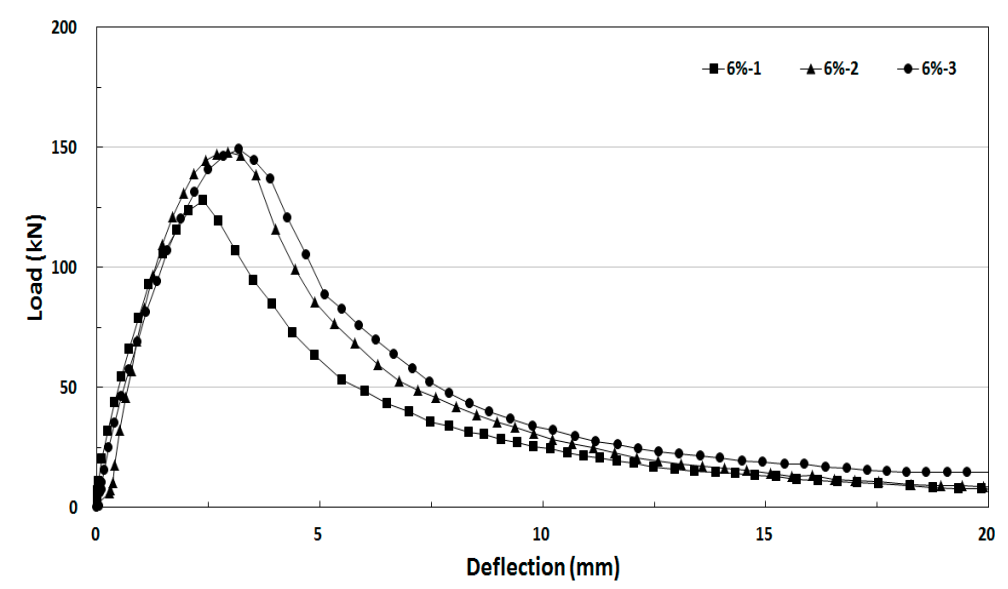

Figure 3. Load-mid span deflection curve at a fiber volume fraction of $6 \%$. 


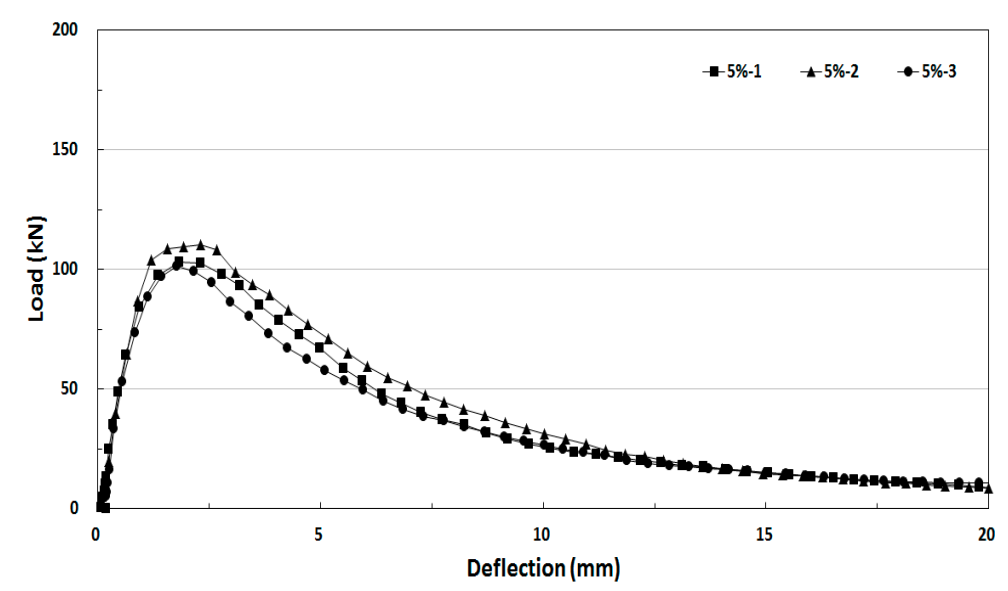

Figure 4. Load-mid span deflection curve at a fiber volume fraction of $5 \%$.

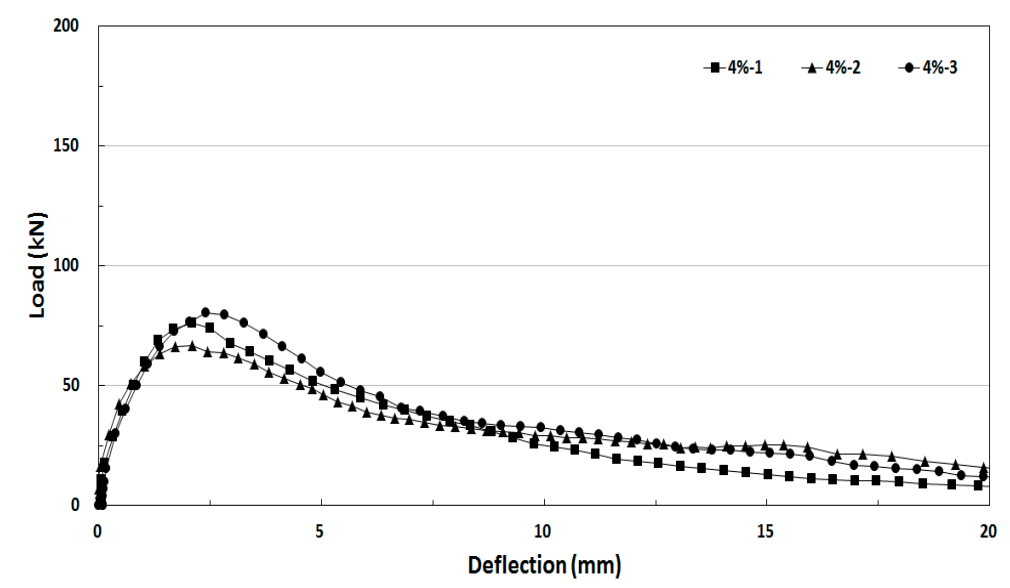

Figure 5. Load-mid span deflection curve at a fiber volume fraction of $4 \%$.

The experimental results showed maximum loads of 111 and $81 \mathrm{kN}$ for the fiber volume fractions of $5 \%$ and $4 \%$, respectively, which were approximately $75 \%$ and $55 \%$ of the maximum load for the fiber volume fraction of $6 \%$. Thus, the maximum load decreased with decreases of the fiber volume fraction. Accordingly, the flexural strength of steel-fiber-reinforced cementitious composites with a high fiber volume fraction were observed to decrease sensitively with respect to the steel-fiber density inside the specimen. Furthermore, the residual strengths for the fiber volume fractions of $6 \%$ and $5 \%$ were similar after a certain deflection. This suggests that the steel-fiber density variation on the fracture section was insignificant above a certain steel-fiber volume fraction and did not greatly affect the residual strength.

The experimental results of flexural behavior characteristics with respect to the fiber volume fraction showed that the load of SIFRCCs tended to continuously increase with respect to fiber volume fraction after the initial crack until they reached the maximum load. Furthermore, the maximum load of every variable occurred at around $2.5 \mathrm{~mm}$ of deflection, regardless of the fiber volume fraction. This implies that the dynamic properties were improved so that the cementitious composites could resist loads (such as an impact) by absorbing sufficient energy even after the initial crack through the bridging effect with respect to high fiber volume fractions. Furthermore, the high-performance slurry increased the steel-fiber bond strength, and the failure mode of the fiber fracturing at the fracture surface occurred along with the fiber-pulling phenomenon.

As described above, owing to the high volume fraction of steel fibers, the specimens showed continuous load resistances with no sudden failures, indicating a desirable deformation capacity. Generally, after failure, fiber volume fraction has a greater effect on flexural toughness rather than on flexural strength. Although the load-deflection curves of the fiber volume fraction were similar in general, the flexural strength showed distinct differences with respect to fiber volume fraction. 
This could be because the composites of steel fibers and the slurry showed homogeneous behaviors owing to the inclusion of relatively large numbers of fibers and the high strength of the slurry due to the high volume fraction of steel fibers. The increase in the fiber volume fraction of SIFRCCs improves the mechanical strength, the residual strength, and especially the toughness. The use of fine aggregates in the binder matrix reduces the water demand of the fresh matrix and increases the flexural strength and brittleness of SIFRCCs. The use of steel fibers in SIFRCCs increases bending tension and shear strength, and makes concrete sufficiently ductile. Thus, SIFRCCs can be considered UHPC.

\subsection{Flexural Strength and Toughness}

Figures 6 and 7 compare the flexural strength and toughness experiment results with respect to the fiber volume fraction. A fiber volume fraction of $6 \%$ showed a high maximum flexural strength of 44.7 MPa. This is a desirable flexural strength that corresponds to approximately $50 \%$ of the compressive strength, suggesting a desirable resistance to bending (unlike conventional fiber-reinforced concrete).

The experimental results for the fiber volume fractions of $5 \%$ and $4 \%$ showed maximum strengths of 33.2 and $24.2 \mathrm{MPa}$, respectively. The maximum flexural strength tended to decrease with decreases in the fiber volume fraction.

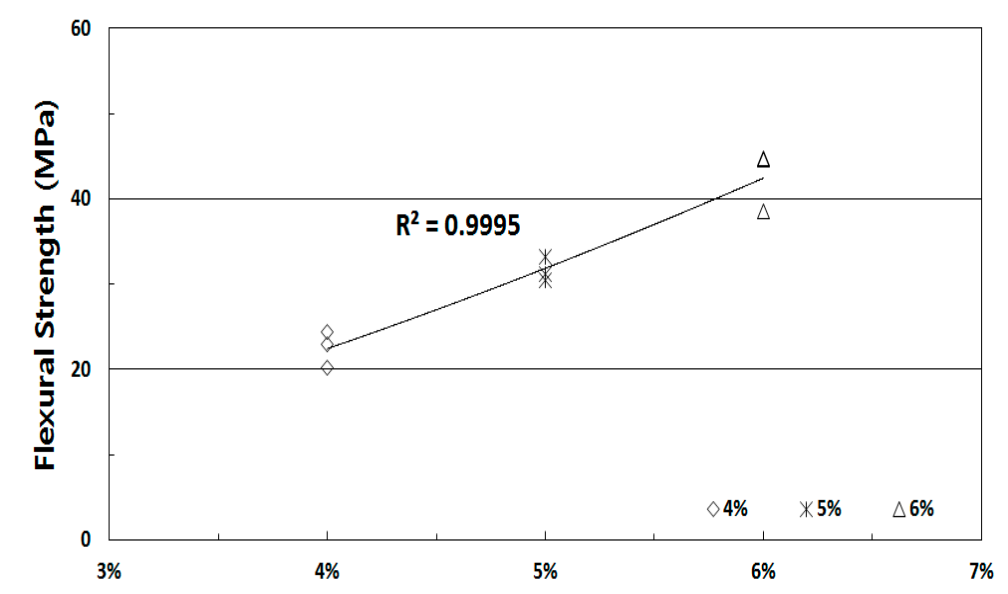

Figure 6. Test results of flexural strength with respect to fiber volume fraction.

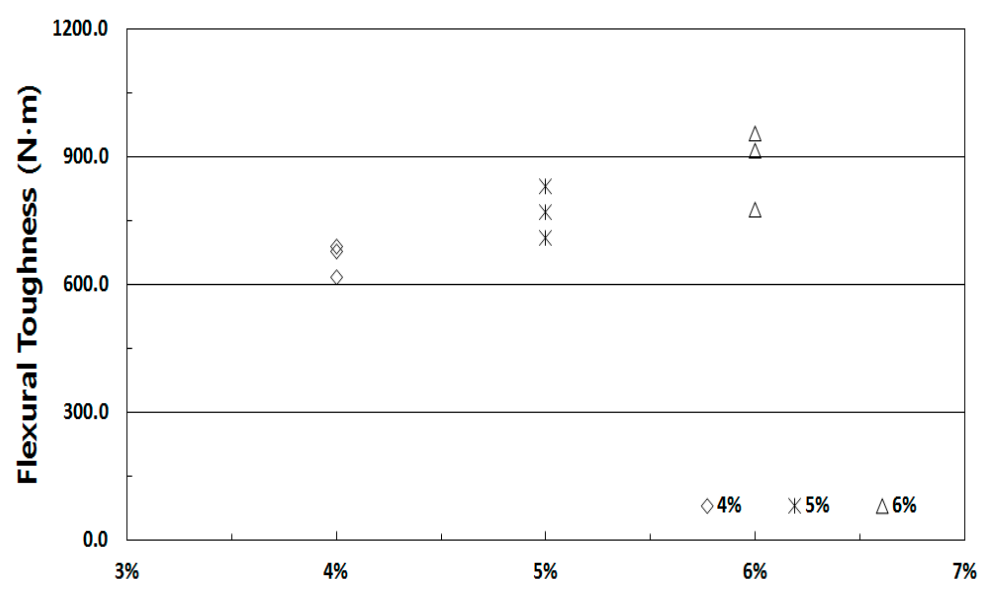

Figure 7. Test results of flexural toughness with respect to fiber volume fraction.

This study attempted to analyze flexural toughness characteristics based on ASTM C 1609 [21]; however, the flexural toughness limited the area to $1 / 150$ of the span distance in the load-deflection curve, as suggested in ASTM C 1609 [21], which was insufficient as the measured deflection greatly exceeded this value. For this reason, the flexural toughness was compared with an area of $20 \mathrm{~mm}$ of deflection (span distance/15). Figure 7 shows the flexural toughness with respect to the fiber volume 
fraction. The comparison of the flexural toughness until $20 \mathrm{~mm}$ of deflection showed an energy absorption capacity of approximately $662 \mathrm{~N} \cdot \mathrm{m}$ at the fiber volume fraction of $4 \%$; however, the capacity was approximately 1.3 times higher (i.e., $882 \mathrm{~N} \cdot \mathrm{m}$ ) at the fiber volume fraction of $6 \%$. The experimental results based on the fiber volume fraction revealed that the flexural toughness tended to increase with the fiber volume fraction, similar to the results of the flexural strength experiment. Table 6 outlines the calculation results of flexural strength and toughness with respect to the fiber volume fraction.

Table 6. Test results of flexural strength and toughness obtained through bending.

\begin{tabular}{|c|c|c|c|c|}
\hline $\begin{array}{c}\text { Variables (Fiber } \\
\text { Volume Fraction) }\end{array}$ & $\begin{array}{c}\text { Flexural Strength } \\
(\mathrm{MPa})\end{array}$ & $\begin{array}{l}\text { Flexural Toughness } \\
(\mathrm{N} \cdot \mathrm{m})\end{array}$ & $\begin{array}{c}\text { Average Flexural } \\
\text { Strength (MPa) }\end{array}$ & $\begin{array}{l}\text { Average Flexural } \\
\text { Toughness (N.m) }\end{array}$ \\
\hline \multirow{3}{*}{$4 \%$} & 22.9 & 616.1 & \multirow{3}{*}{22.5} & \multirow{3}{*}{661.8} \\
\hline & 20.2 & 678.8 & & \\
\hline & 24.4 & 690.6 & & \\
\hline \multirow{3}{*}{$5 \%$} & 31.1 & 769.4 & \multirow{3}{*}{31.6} & \multirow{3}{*}{770.4} \\
\hline & 33.2 & 831.3 & & \\
\hline & 30.4 & 710.6 & & \\
\hline \multirow{3}{*}{$6 \%$} & 38.5 & 776.5 & \multirow{3}{*}{42.6} & \multirow{3}{*}{881.7} \\
\hline & 44.6 & 914.0 & & \\
\hline & 44.7 & 954.6 & & \\
\hline
\end{tabular}

The analysis of flexural strength and toughness showed that the behavioral characteristics obtained from the experimental research differed slightly from the general tendency of the fiber volume fraction to greatly affect the fracture toughness after an initial crack or maximum load. This is because the combined action of the high fiber volume fraction and matrix strength of the cement composites in this study not only increased the fracture toughness, but also greatly affected flexural strength. Therefore, to achieve the performance required to increase resistance to impact or explosion loads, it would be advantageous to maintain the fiber volume fraction at the highest level through construction, so as to increase flexural strength and toughness.

\section{Conclusions}

In this study, the flexural behavior characteristics of SIFRCCs were analyzed with respect to variations in fiber volume fraction used to improve the resistance performance of reinforced concrete (RC) structures to unexpected loads such as explosions or impacts. The following conclusions can be drawn from this study:

(1) The load of the SIFRCCs with respect to the fiber volume fraction continuously increased because of the high fiber volume fraction after the initial crack, and sufficient residual strength was obtained after the maximum strength. This sufficient residual strength is expected to bring about positive effects to the brittle fracture of structures when unexpected loads, such as explosion and impact, are applied.

(2) The maximum flexural strength at the fiber volume fraction of $6 \%$ was about $45 \mathrm{MPa}$, which is a desirable flexural resistance performance corresponding to approximately $50 \%$ of the compressive strength. In contrast, the maximum flexural strength at the fiber volume fraction of $4 \%$ was $24 \mathrm{MPa}$. Thus, a large difference was observed in the flexural strength with respect to the fiber volume fraction.

(3) The results of the flexural toughness and flexural strength experiments showed a similar trend, and the fiber volume fraction greatly affected the energy absorption capacity. Furthermore, in the event of a fracture, the fibers also fractured and the fiber-pulling phenomenon occurred on the fracture surface. This suggests that the sufficiently high bond performance between the steel fibers and high-performance slurry increased the fracture energy. 
(4) The shapes of the load-deflection curves plotted with respect to the fiber volume fraction were similar. However, the fiber volume fraction had a greater effect on the magnitude of flexural strength. This could be because the composites of steel fibers and high-performance slurry had homogeneous behaviors due to a relatively large number of steel fibers that were included (increasing the high fiber volume fraction); thus, the slurry strength increased.

(5) To meet the required performance for increasing resistance to explosions and impact loads, the energy absorption capacity would benefit from maintaining the fiber volume fraction at the highest level through constructions, so as to increase flexural strength and toughness. Furthermore, more economical use of steel fibers requires the determination of the fiber aspect ratio and volume fraction, as it reflects the required characteristics of the structures against impact and explosion loads.

Author Contributions: Conceptualization, S.K., C.P., and Y.K.; methodology, S.K., C.P., and Y.K.; writing一original draft preparation, S.K. and C.P.; writing-review \& editing, S.K., C.P., and Y.K. All authors have read and agreed to the published version of the manuscript.

Funding: This research was supported by a grant (20SCIP-B146646-03) from the Construction Technology Research Project funded by the Ministry of Land, Infrastructure and Transport of Korea government and by Basic Science Research Program through the National Research Foundation (NRF) of Korea funded by the Ministry of Education (NRF-2019R1I1A1A01062942).

Conflicts of Interest: The authors declare no conflicts of interest.

\section{References}

1. Kim, S.; Jung, H.; Kim, Y.; Park, C. Effect of steel fiber volume fraction and aspect ratio type on the mechanical properties of SICON-based HPFRCC. Struct. Eng. Mech. 2018, 65, 167-171.

2. Kim, S.; Kim, D.J.; Kim, S.-W.; Park, C. Tensile Behavior Characteristics of High-Performance Slurry-Infiltrated Fiber-Reinforced Cementitious Composite with respect to Fiber Volume Fraction. Materials 2019, $12,3335$. [CrossRef] [PubMed]

3. Kim, S.; Han, S.; Yun, K.-K.; Park, C. Compressive Behavior Characteristics of High-Performance Slurry-Infiltrated Fiber-Reinforced Cementitious Composites (SIFRCCs) under Uniaxial Compressive Stress. Materials 2020, 13, 159. [CrossRef] [PubMed]

4. Ku, D.-O.; Kim, S.-D.; Kim, H.-S.; Choi, K.-K. Flexural Performance Characteristics of Amorphous Steel Fiber-Reinforced Concrete. J. Korea Concr. Inst. 2014, 26, 483-489. [CrossRef]

5. Naaman, A.E. Toughness, Ductility, Surface Energy and Deflection-Hardening FRC Composites. In Proceedings of the JCI International Workshop on Ductile Fiber-Reinforced Cementitious Composites (DRFCC)-Application and Evaluation (DFRCC-2002), Takayama, Japan, 21-22 October 2002; pp. 33-57.

6. Banthia, N.; Sappakittipakorn, M. Toughness Enhancement in the Steel Fiber Reinforced Concrete through Fibers Hybridization. Cem. Concr. Res. 2007, 37, 1366-1372. [CrossRef]

7. Lee, Y.-O.; Yun, H.-D. Effects of Expansive Admixture on the Mechanical Properties of Strain-Hardening Cement Composite (SHCC). J. Korea Concr. Inst. 2010, 22, 617-624. [CrossRef]

8. Metha, P.K.; Monreiro, P.J. Concrete: Microstructure, Properties and Materials, 3rd ed.; McGraw-Hill, Inc.: New York, NY, USA, 2006; pp. 502-522.

9. Kim, S.; Park, C. Flexural Behavior of High-Volume Steel Fiber Cementitious Composite Externally Reinforced with Basalt FRP Sheet. J. Eng. 2016, 2016, 2857270. [CrossRef]

10. Kim, S.-W.; Park, C.-W.; Kim, S.-W.; Cho, H.-M.; Jeon, S.-P.; Ju, M.-K. Optimum Mix Proportions of In-Fill Slurry for High Performance Steel Fiber Reinforced Cementitious Composite. J. Korean Recycl. Constr. Resour. Inst. 2014, 2, 196-201.

11. Park, C.; Kim, Y.; Choi, E.; Kim, S. Fundamental properties and mechanical characteristics of high performance cement composite with steel fibers under high temperature. J. Struct. Integr. Maint. 2016, 1, 189-196.

12. Kim, S.-W.; Cho, H.-M.; Lee, H.-Y.; Park, C.-W. Flexural Performance Characteristics of High Performance Slurry Infiltrated Fiber Reinforced Cementitious Composite according to Volume Fraction. J. Korea Inst. Struct. Maint. Insp. 2015, 19, 109-115. 
13. Schmidit, M.; Fehling, E. Ultra-high-Performance Concrete: Research, Develpoment and Application in Europe. ACI Spec. Publ. 2005, 228.

14. Soulioti, D.V.; Barkoula, N.M.; Paipetis, A.; Matikas, T.E. Effects of Fiber Geometry and Volume Fraction on the Flexural Behaviour of Steel-Fibre Reinforced Concrete; Department of Materials Engineering, University of Ioannina: Ioannina, Greece, 2011.

15. Meng, W.; Valiour, M.; Khayat, K.H. Optimization and performance of cost-effective ultra-high performance concrete. Mater. Struct. 2017, 50, 129-139. [CrossRef]

16. Meng, W.; Khayat, K.H. Effects of saturated lightweight sand content on key characteristics of ultra-high-performance concrete. Cem. Concr. Res. 2017, 101, 46-54. [CrossRef]

17. Malvar, L.J.; Crawford, J.E.; Morrill, K.B. Use of Composites to Resist Blast. J. Compos. Constr. 2007, 11, 601-610. [CrossRef]

18. Bindiganavile, V.; Banthia, N. Generating dynamic crack growth resistance curves for fiber reinforced concrete. Exp. Mech. 2005, 45, 112-122. [CrossRef]

19. Cho, H.-M.; Kim, S.-W.; Song, J.-H.; Park, H.-M.; Park, C.-W. Experimental Study on Mechanical Properties of Carbon-Capturing Concrete Composed of Blast Furnace Slag with Changes in Cement Contents and Exposure. Int. J. Highw. Eng. 2015, 17, 41-51. [CrossRef]

20. Kim, S.; Park, C. Flexural Behavior Characteristics of High Performance Slurry Infiltrated Fiber Reinforced Cementitious Composite with Respect to Exposure to High Temperature. J. Korea Concr. Inst. 2019, 31, 139-146. [CrossRef]

21. American Society for Testing and Materials (ASTM). Standard Test Method for Flexural Performance of Fiber-Reinforced Concrete (Using Beam with Third-Point Loading); ASTM C 1609; ASTM: West Conshohocken, PA, USA, 2012.

22. Ghosni, N.; Samali, B.; Valipour, H. Flexural behaviour of high strength concrete composite incorporating long hooked-end steel fibres. In Proceedings of the 23rd Australasian Conference on the Mechanics of Structures and Materials, Byron Bay, Australia, 9-12 December 2014; pp. 327-332.

(C) 2020 by the authors. Licensee MDPI, Basel, Switzerland. This article is an open access article distributed under the terms and conditions of the Creative Commons Attribution (CC BY) license (http://creativecommons.org/licenses/by/4.0/). 